Int. J. Electrochem. Sci., 12 (2017) $618-628$

International Journal of

ELECTROCHEMICAL

SCIENCE

WwW.electrochemsci.org

\title{
Green Biosynthesis of CdS Nanoparticles Using Yeast Cells for Fluorescence Detection of Nucleic Acids and Electrochemical Detection of Hydrogen Peroxide
}

Huan Feng ${ }^{1}$, Shi-yong Liu $^{2}$, Xiao-bing Huang ${ }^{3}$, Ran Ren ${ }^{4}$, Yan Zhou ${ }^{3}$, Cai-ping Song ${ }^{1 *}$ and De-hui Qian $^{5 *}$

${ }^{1}$ Division of Nursing, Second Hospital Affiliated to Third Military Medical University. XinQiao Hospital, ChongQing 400037, China

${ }^{2}$ Department of Neurosurgery, Second Hospital Affiliated to Third Military Medical University. XinQiao Hospital, ChongQing 400037, China

3 Department of Hepatobiliary Surgery, Second Hospital Affiliated to Third Military Medical University. XinQiao Hospital, ChongQing 400037, China

${ }^{4}$ Departement of Scientific Research, Second Hospital Affiliated to Third Military Medical University. XinQiao Hospital, ChongQing 400037, China

5 Departement of Cardiology, Second Hospital Affiliated to Third Military Medical University. XinQiao Hospital, ChongQing 400037, China

*E-mail: qiandehui@163.com

doi: $10.20964 / 2017.01 .57$

Received: 19 October 2016 / Accepted: 18 November 2016 / Published: 12 December 2016

In this work, a green method was reported to biosynthesize the CdS nanoparticles, where the yeast Saccharomyces cerevisiae was used as the nitrogen source. To characterize the as-prepared CdS NPs, UV-Vis spectroscopy, XRD and SEM were employed. The results indicated that the as-synthesized CdS NPs from Saccharomyces cerevisiae exhibited a mean size of $4.7 \mathrm{~nm}$ with high purity. The electrochemically detection of hydrogen peroxide and fluorescence-enhanced detection can be achieved by the application of biosynthesis CdS nanoparticles.

Keywords: Biosynthesis; CdS NPs; TEM; Fluorescence detection; Sachharomyces cerevisiae; Hydrogen peroxide

\section{$\underline{\text { FULL TEXT }}$}


(C) 2017 The Authors. Published by ESG (www.electrochemsci.org). This article is an open access article distributed under the terms and conditions of the Creative Commons Attribution license (http://creativecommons.org/licenses/by/4.0/). 